ron 75 factores de riesgo con cuatro intervenciones o más. Algunas intervenciones estaban dirigidas a más de una enfermedad, pero no se encontraron intervenciones dirigidas contra tres $(9,7 \%)$ de las enfermedades estudiadas (artritis, cáncer de próstata y pérdida de la audición).

No se encontraron pruebas científicas suficientes para poder evaluar la eficacia de las intervenciones diseñadas para reducir el riesgo de las principales causas de enfermedad, lesión y discapacidad.

Estos resultados subrayan la necesidad de investigar la eficacia de intervenciones poblacionales específicas y de realizar revisiones sistemáticas a fin de reunir pruebas científicas que demuestren su utilidad en relación con enfermedades importantes para la salud pública.

¿Cuál sería, entonces, la agenda para lograr una salud pública basada en pruebas científicas? En primer lugar, se requieren investigaciones básicas que evalúen los diversos indicadores de la carga de enfermedad y que permitan identificar las brechas en los datos acerca del riesgo atribuible. Segundo, se deben investigar las enfermedades y los factores de riesgo modificables para poder identificar las intervenciones basadas en datos probatorios. Tercero, se deben diseñar investigaciones metodológicas que permitan evaluar el efecto de múltiples intervenciones sobre una misma enfermedad y los resultados de una intervención sobre diferentes enfermedades. Por último, se deben evaluar la eficacia, la utilidad y los beneficios de estas intervenciones en función del costo, para decidir cuáles políticas son aplicables en cada nivel del sistema de salud pública.

Los especialistas en salud pública deben hacer frente de una manera más creativa a las complejidades metodológicas que se presentan. Los estudios observacionales o cuasiexperimentales son más prácticos en el contexto de la salud pública que los ensayos aleatorizados y se debe mostrar una mayor flexibilidad en la aplicación de nuevos conocimientos. Para enfrentar estos retos metodológicos, es necesario entrenar a más investigadores en diversas disciplinas relacionadas con la salud pública, entre ellas la epidemiología, las ciencias sociales y conductuales, y la economía. (Thacker SB et al. The evidence base for public health informing policy at the Centers for Disease Control and Prevention. Am J Prev Med. 2005;28(3):227-33).

\section{Importantes aportes al conocimiento del dengue y dengue hemorrágico}

Desde finales de la década de 1970, Cuba ha sido azotada por varias epidemias de dengue. Este artículo representa una crónica de los logros alcanzados por los investigadores del Instituto de Medicina
Tropical Pedro Kourí (IPK), de La Habana, Cuba, a lo largo de más de 20 años. Las investigaciones realizadas por este centro han contribuido notablemente a ampliar el conocimiento actual sobre la patogenia, el diagnóstico, la epidemiología y las manifestaciones clínicas de esta enfermedad.

La primera epidemia de dengue hemorrágico en las Américas se presentó en Cuba en 1981 con más de 344000 casos; de ellos, unos 10000 se consideraron graves o muy graves. Esta epidemia, causada por el virus del dengue tipo 2, provocó 158 muertes, 101 de ellas en niños. El dengue hemorrágico es la forma más letal de dengue y antes de 1981 solo se habían informado 60 casos en toda la Región.

Las investigaciones realizadas en el IPK a partir de ese momento condujeron a importantes conocimientos epidemiológicos, virológicos y clínicos. En primer lugar, el estudio de las tres epidemias de dengue hemorrágico que han afectado a Cuba (en 1981, 1997 y 2001-2002) ha confirmado que la infección secundaria es grave en más de $97 \%$ de los casos.

Contrario a lo que se pensaba con anterioridad, estos estudios han demostrado que los casos graves pueden ocurrir aun habiendo transcurrido varias décadas entre la infección inicial por el virus del dengue tipo 1 y la infección secundaria por el virus tipo 2. Eso significa que una vacuna realmente eficaz debe proteger contra los cuatro serotipos de dengue a largo plazo, ya que de lo contrario, la propia vacuna podría sensibilizar a los vacunados y provocar dengue hemorrágico grave ante una infección secundaria por un serotipo diferente.

Con relación a los factores de riesgo de las formas graves de dengue, se demostró que las personas con enfermedades crónicas - como asma bronquial, diabetes mellitus y drepanocitosis - tienen una mayor probabilidad de contraer el dengue hemorrágico. Un aporte novedoso es que la forma hemorrágica se ha observado en Cuba predominantemente en personas de la raza blanca. La edad entre los 3 y 14 años también es un factor de riesgo.

Las investigaciones realizadas por este grupo también demostraron que el virus asociado con las epidemias de dengue hemorrágico en Cuba pertenece a un genotipo asiático, y documentaron la presencia de un patrón evolutivo en algunos genes. También han encontrado un alto grado de conservación en los genes que codifican proteínas estructurales y en la secuencia de las regiones no codificantes del genoma vírico.

Datos preliminares han demostrado que la presencia de anticuerpos producidos contra un serotipo de dengue diferente del que provoca la infección ayuda a reducir la gravedad de la enfermedad. Estos anticuerpos desaparecen con el tiempo, lo que puede explicar por qué las infecciones secundarias producen con frecuencia casos más graves que la 
infección primaria. También demostraron el importante papel que desempeña la interleucina 10 en la patogenia del dengue, poniéndose de manifiesto la relación directa de la infección secundaria con la respuesta inmunitaria no inflamatoria. Estos resultados abren nuevos caminos para la investigación.

En el campo de las vacunas, este grupo de investigadores fue el primero en evaluar la utilidad de una proteína recombinante expresada en la levadura Pichia pastoris. Esta proteína estimuló la producción de anticuerpos neutralizantes contra el virus del dengue en monos, observándose la protección parcial de los animales ante la prueba de reto con el virus silvestre. Evaluaciones preliminares demostraron también la posibilidad de utilizar fragmentos proteínicos del virus del dengue para producir una respuesta inmunitaria protectora en animales.

Estos resultados deben ayudar a detener la diseminación de esta enfermedad reemergente en nuestra Región y a encontrar mejores métodos para su diagnóstico, tratamiento y control. (Guzmán MG. Deciphering dengue: the Cuban experience. Science. 2005;309(5740):1495-7).

\section{El paludismo y la pobreza}

El paludismo se concentra en los países más pobres del mundo y $90 \%$ de las defunciones correspondientes ocurren en el África subsahariana. Para determinar la distribución del paludismo en diferentes estratos socioeconómicos, se hizo una revisión bibliográfica de publicaciones posteriores a 1990, si bien se incluyó también "literatura gris". En la revisión se incluyeron 50 de los estudios encontrados, la mayor parte sobre países africanos. Aunque la relación entre el paludismo y la equidad debe interpretarse a la luz de toda la literatura sobre la salud y la equidad, la restricción del análisis a estudios sobre el paludismo se justifica a la luz de las iniciativas internacionales que enfocan esta enfermedad en el contexto de la equidad (el Fondo Mundial de Lucha contra el Sida, la Tuberculosis y la Malaria; la Asociación para la Reducción de la Malaria; los Objetivos de Desarrollo del Milenio) y también porque hay formas de combatir la enfermedad que no siempre se llevan a cabo por conducto de los servicios de salud. Sirven de ejemplo los mosquiteros tratados con insecticidas y la detección de casos mediante los servicios sociales. No obstante, el tema corresponde a la entrega de servi- cios de salud y cada análisis ayuda a comprender mejor la equidad en la distribución de los servicios que se refieren al paludismo.

Al estimar la pobreza, los economistas suelen emplear el consumo doméstico como criterio de referencia. Es menos propenso a fluctuación que el ingreso, pero difícil de medir. Por otra parte, es posible que la pobreza, de naturaleza multidimensional, no pueda definirse solamente en función del dinero. Recientemente se han usado índices de riqueza que se construyen de un pequeño número de variables. A veces se emplean otros indicadores como escolaridad, sexo, residencia urbana o rural y ocupación. Ninguno es perfecto. Un problema importante es tener que depender de la medición de la pobreza usada en cada estudio. Otras dificultades son la falta de un método común para comparar los resultados de los estudios, la endogenia entre el paludismo y la pobreza, que soslaya la causalidad en ambas direcciones, y la subestimación de la relación entre la situación socioeconómica y la incidencia del paludismo.

En un estudio de ámbito regional que combinaba datos de 29 encuestas en 22 países, se encontró una asociación directa no significativa entre la fiebre del paludismo y la pobreza en el África central y occidental. La relación fue significativa $(P<0,10)$ en el África oriental y del sur, y en mayor grado si se excluía a Madagascar $(P<0,05)$. Sin embargo, análisis ulteriores mostraron una relación más importante con la escolaridad materna. Considerando al niño individualmente, la relación entre la fiebre y el ingreso familiar fue negativa y no significativa en el África central y occidental y significativamente negativa $(P<0,10)$ en el África oriental y del sur. Estos resultados no fueron significativos cuando se controló el efecto del grado de fiebre en una veintena de domicilios. La relación entre la fiebre y el ingreso familiar en otros domicilios fue significativamente negativa en África oriental y del sur, pero no en el centro ni occidente del continente. La fiebre infantil individual se relacionó positivamente $(P<0,05)$ con la de otros niños en grupos de caseríos. En estudios basados en combinaciones de la ocupación, el estado nutricional, la posesión de ganado, el acceso a la electricidad y subsidios de alimentación, se observó una relación en la dirección de la hipótesis. En los que se contemplaron los ingresos, la escolaridad y la ocupación, no hubo una relación significativa entre la fiebre y la pobreza. (Worral E et al. Is malaria a disease of poverty? A review of the literature. Trop Med Int Health 2005;10:1047-62). 